\title{
The Role of Jordanian Public Universities in Promoting International Educational Principles from the Perspective of their Faculty Members
}

\author{
Yasmin Mesleh Al-Aqrabawi ${ }^{1} \&$ Mohammad Saleem Al-Zboon ${ }^{2}$ \\ ${ }^{1} \mathrm{Ph}$ Student. in Educational Foundations the University of Jordan, Amman, Jordan \\ ${ }^{2}$ Prof. in Educational Foundations, Faculty of Educational Sciences, The University of Jordan, Amman, Jordan \\ Correspondence: Mohammad Saleem Al-Zboon, Prof. in Educational Foundations, Faculty of Educational \\ Sciences, The University of Jordan, Amman, Jordan. E-mail: m.alzboon@ju.edu.jo
}

Received: Oct. 24, 2018

Accepted: Nov. 5, $2018 \quad$ Online Published: December 15, 2018

doi:10.5539/mas.v13n1p116

URL: https://doi.org/10.5539/mas.v13n1p116

\begin{abstract}
The present study aimed at exploring the role of Jordanian public universities in promoting international educational principles from the perspective of their faculty members. In order to meet the study's goals, a descriptive approach was adopted and a questionnaire was developed. The questionnaire consists from twenty five (25) items. The validity and reliability of the questionnaire were measured. The study's sample consists from three hundred (300) faculty members. They were selected from three Jordanian public universities (i.e. the University of Jordan, Yarmouk University and Mu'tah University). The researchers concluded the following results:

1)- The Jordanian public universities play a moderate role in promoting international educational principles from the perspective of the faculty members

2)- There isn't any statistically significant difference between the respondents' attitudes towards the role of Jordanian public universities in promoting international educational principles which can be attributed to gender. However, there are statistically significant differences between the respondents' attitudes in this regard which be attributed to their academic rank. The latter differences are for the favor of the associate professors. There are statistically significant differences between the respondents' attitudes in this regard which be attributed to type of faculty. The latter differences are for the favor of the ones who work in scientific faculties.

The researchers of the present study recommend exerting more efforts by the administrations of Jordanian public universities to promote international educational principles. They also recommend providing more attention for international education in Jordanian universities. That should be done through holding seminars in order for faculty member to attend and hold discussions about international educational principles and concepts. Such seminars shall enrich the knowledge that faculty members have in this regard. The researchers also recommend promoting awareness among faculty members about the significance of addressing international education-related issues in their lectures.
\end{abstract}

Keywords: Jordanian Universities, international education, the faculty members

\section{Introduction:}

Several changes have been witnessed, and technological developments and knowledge have been increasing. In addition, borders have been broken down between countries. Thus, the world has become a small village. In the light of such changes, it has become necessary to promote awareness among nations about the significance of building a common future that units them together. Building such a future has become necessary in the light the contemporary challenges.

It should be noted that international problems are not restricted any more to one county only. In fact, such problems have become global in terms of causes, results and consequences. Therefore, it has become necessary to address these problems. However, that requires having knowledge and values by the members of each nation. In addition, addressing such problems requires promoting international educational principles. Promoting such principles shall participate in establishing good international relationships that are based on mutual understanding. It shall also participate in the advancement of civilizations.

Changes have been occurring rapidly. For instance, globalism has been spreading. It has become easily to exchange 
ideas, services, products and knowledge. Cultural and intellectual diversity have been increasing. Openness to the other and interacting with him have been increasing too. People's ways of thinking have been changing. Knowledge has been exchanged due to the spread of technology (Al Eid, AlZboon,2018). Borders have been broken down and news can be known on the spot. People are influencing the other and the other is influencing them. In the light of such changes, it has become necessary to promote new international educational principles and master foreign languages. It has also become necessary to have greater knowledge about various cultures (Yas, 2002).

University education is a source of power for any community. For instance, education provides people with knowledge, skills, values, orientations and capabilities. That shall enable people to address current and future challenges. It should be noted that development and advancement can be achieved in any community, if it has good intellectual outcomes. Therefore, countries should improve the quality of their university education. In addition, universities should provide international education through their educational system. They should also integrate international educational principles in their educational programs and curricula. That should be done because human capital is the real wealth in the contemporary age. Such a wealth can increase through empowering students, promoting knowledge among them about the contemporary changes, and enabling them to participate in these changes (Azab, 2011).

International education involves several principles. For instance, it involves promotion of cooperation and integration between nations. That can be done through promoting awareness about the fact that people share the same origin. Therefore, one must show respect to the other and avoid showing any act of discrimination. International educational principles also involve promotion of equality and justice between humans in terms of rights, duties, jobs, treatment and opportunities. Such a promotion is considered a global and regional demand. International educational principles also involve promotion of respect for human rights. Such rights include: one's right to receive education, own things, live, and benefit from things. Such rights include one's right to usufruct things and express opinion. Such rights also include freedom of religion and showing respect for minorities.

In other words, International educational principles also involve promoting respect for human rights and humans regardless of one's race, beliefs and thoughts. Such principles also involve promotion of respect for the other's religion and acceptance for sectarian diversity. Such principles also involve promoting of peaceful coexistence and toleration. That can be done through eliminating latent grudges within people (Jaydoory, 2012).

International education seeks promoting many principles and values. For instance, international education aims to promote toleration, peace and peaceful coexistence. It also aims to promote a sense of creativity, and acceptance for multiculturalism. It also aims to promote valuing for heritage. In addition, it seeks providing one with adequate skills and capabilities that enable him to use modern technology efficiently. The latter education seeks providing one with adequate skills and capabilities that enable him to produce and distribute information in a manner that shall benefit humanity (Abed Al-Hay, 2013).

There is a variety of international education fields. For instance, there is afield of international education that is concerned with peace and security. The latter education shall promote toleration and rejection for violence. Another field is the international education that seeks disarming people. The latter field seeks promoting feelings of rejection to war among the ones who consider it a mean for settling disputes. Another field is the international education that seeks promoting development. The latter field seeks establishing relationships between developed and developing countries and afair international system. Another field is the international education that seeks promoting citizenship values. The latter field seeks promoting feelings of loyalty and belonging to homeland. It also seeks promoting awareness among people about their duties and responsibilities towards their society. Another field is the international environmental education. The latter field seeks promoting knowledge about nature and global environment as being a common cultural heritage. It also seeks promoting knowledge about the way of protecting the environment. Another field is the international education that seeks promoting knowledge about cultural, social, economic, and political human rights. It seeks promoting respect to such rights in accordance with the Universal Declaration of Human Rights and international conventions. Another field is the international multicultural education. It seeks promoting understanding for foreign cultures, and other nations' customs, beliefs, values and orientations (Lasheen, and Abed Al-Jawad, 2012).

International education aims to promote educational knowledge and develop positive educational orientations. It aims to promote an international respect for cultures, customs and traditions of every nation and civilization. In addition, it aims to promote respect for human rights and freedoms which are stipulated in international conventions, declarations and covenants. International education plays a significant role. For instance, it enables the society - regardless of its social, economic, and political systems - to become free of violence, decimation and 
armed dispute. It also serves as a tool that promotes respect for all societies and humans regardless of one's color, gender, beliefs, customs or traditions (Al-Milad, 2013).

International education has been given different names in international conferences and conventions. For instance, it has been called: academic movement, international cooperation, multicultural education, peace education, transcultural education, internationalization of education, globalization of education, and global citizenship education. The latter field of education emerged at the end of the $20^{\text {th }}$ century and the beginning of the $21^{\text {st }}$ century. Other names for international education may include: education for international understanding. UNESCO used the latter term. Other names for international education may include global education. The latter term is widely used in the United States of America (Al-Kaltham, 2016).

International education is associated with many values, issues, problems and nations' history. Many organizations take up international educational causes. Such causes include: international peace, human rights, democracy, toleration, global citizenship, international understanding, cross-cultural education, and environmental causes. It should be noted that international education aims to promote international cooperation, peace, and understanding. It aims to achieve that through encouraging people to launch projects that can achieve such goals (Al-Shal, 2012).

International education has been facing many challenges. Such challenges include scientific advancement. These challenges have increased after witnessing an increase in the number of scientific branches. They have increased after connecting scientific fields with one another through modern technological channels. They have increased after witnessing several economic transformations. Such transformations occurred due to the developmental programs that were carried out by developed countries in developing countries.

In addition, these challenges have increased after witnessing several political transformations. Such transformations have turned national problems into international ones. Therefore, it has become necessary to find solutions for international problems because they affect several countries. The challenges facing international education have been increasing due to witnessing several social transformations. Such transformations required keeping up with social developments, and acquiring values that are necessary in the modern civil society. These values can be acquired through educational systems (Al-Buhy, 2014).

Similar to other universities, the administrations of Jordanian public universities believe that it's highly important to promote toleration and acceptance for other cultures through education. The latter administrations also aim to promote cultural awareness among students. They also aim to promote recognition among students for their cultural identity. They also aim to promote a sense of creativity and innovation among students in accordance with global values. They aim to achieve that through encouraging students to search, explore and investigate things.

The Jordanian public universities aim to develop students' skills and enable them to acquire knowledge. They also aim to enable students to employ their skills in many academic and practical fields. They also aim at promoting international cooperation and encouraging students to participate in solving problems. In addition, Jordanian public universities aim at enabling students to respond to the global requirements in a manner that shall benefit their home country (Al-Tarawneh, 2010).

However, the dominant educational culture in Jordanian universities is still a conventional culture. For instance, the latter universities do not employ means for promoting international educational principles. In such universities, these principles are promoted through a limited number of courses. Hence, these universities must benefit from other universities. They must also create an international educational culture through which international educational principles can be promoted. In the light of the aforementioned, the present study aimed to explore the role of Jordanian public universities in promoting international educational principles from the perspective of the faculty members

\section{Statement of the Problem}

The present study aimed to provide an answer to the following question:

(What is the role of Jordanian public universities in promoting international educational principles from the perspective of the faculty members?)

\subsection{The Study's Objectives and Questions}

The present study aimed at identifying the role of Jordanian public universities in promoting international educational principles from the perspective of the faculty members. In order to achieve the study's goals, the researchers aimed to provide answers to the following questions:

Q.1)- What is the role of Jordanian public universities in promoting international educational principles from the perspective of the faculty members? 
Q.2)- Is there any statistically significant difference between respondents' attitudes which can be attributed to their gender, type of faculty, or academic rank?

\subsection{The Study's Significance}

The researchers of the present study believe that the present study shall be useful for:

1)- The Jordanian Ministry of Higher Education: The present study shall encourage the latter ministry to promote awareness among universities' administrations about the significance of promoting and adopting international educational principles and complying with them.

2)- Universities: The present study shall provide universities with information about the significance of having courses that promote toleration and rejection for violence. It shall encourage universities to increase extracurricular activities that encourage students to adopt international educational principles.

3)- Researchers: The present study shall provide researchers with a theoretical framework about the role of Jordanian public universities in promoting international educational principles from the perspective of the faculty members.

\subsection{Definition of Terms}

The researchers provided definitions for the following terms:

1)-Jordanian universities: They refer to educational institutions that are affiliated with the Jordanian Ministry of Higher Education. Jordan includes eleven (11) public universities. Such universities include: the University of Jordan, Yarmouk University and Mu'tah University.

2)-International education: It is an educational field that seeks promoting acceptance for people regardless of their national or regional ideologies. This education involves promoting several international values. It deals with human being as being a global citizen. It aims to promote peace, cooperation, and mutual understanding between nations. It also aims to establish good relationships between nations which vary from one another in terms of social and political views and activities. It also aims to promote respect for human rights and freedoms. It also aims to promote knowledge about the rights recognized through the UN charter and the Universal Declaration of Human Rights (Ismai'l, 2016).

International education (the operational definition): It refers to an education that Jordanian universities seek providing. They seek providing it in the aim of promoting global values, such as: peace, toleration, and respect for minorities and human rights, cooperation with the other. Such values include respect for the culture of dialogue. Jordanian universities seek providing such education in a way that is in agreement with the cultural identify of students.

3)- The faculty members: This expression refers to the ones who teach at Jordanian universities and hold a PhD degree. They vary in terms of academic ranks. Such ranks include the following: lecturer, professor, associate professor, and assistant professor (Al-Hazaymeh, 2017).

\subsection{The Study's Limits}

These limits are represented in the following:

1)- Human limits: The sample of the present study is restricted to the faculty members who work in three Jordanian public universities; the University of Jordan, Yarmouk University and Mu'tah University.

2)- Temporal limits: The present study was conducted during the academic year of (2018 / 2019).

3)- Spatial limits: These limits refer to the University of Jordan, Yarmouk University and Mu'tah University

\section{Previous Studies}

The researchers of the present study reviewed several relevant Arab and foreign studies. They are listed below and arranged in a chronological order from the oldest to the newest:

\subsection{Arab Studies}

Jaydoory (2012) aimed to explore the role of faculty members in promoting global citizenship values among students. The latter study was conducted at Taibah University. A descriptive approach was adopted and a questionnaire was developed to meet the study's goals. The sample of the latter study involves all the faculty members who work at Taibah University. It was found that there is a statistically significant difference between the respondents' attitudes which can be attributed to their major. The latter difference is for the favor of the ones who are specialized in educational sciences. It was found that there is a statistically significant difference between the respondents' attitudes which can be attributed to their gender. The latter difference is for the favor of 
males. It was found that there isn't any statistically significant difference between the respondents' attitudes which can be attributed to their academic rank.

Nasr (2013) aimed to shed a light on human communities' characteristics and cultural diversity. She suggests that the nature of the educational system that the community adopts is the result of the challenges that are faced by that community. She suggests that education is the mean for achieving development within any developing community. In addition, she suggests that providing international education shall add a value to the educational system. She adds that international education shall participate in generating new educational visions.

Al-Kaltham (2016) aimed to explore the extent of listing global educational concepts in the social and national sciences curricula of the intermediate stage in Saudi schools. A descriptive approach was adopted and a questionnaire was used for meeting the study's goals. The study's population involves all the national and social sciences female teachers of the intermediate stage in Saudi schools in Al Majma'ah. It was found that the extent of availability of global educational concepts in the latter curricula is moderate. In addition, it was found that the extent of promoting knowledge about these concepts is moderate from the perspective of the national and social sciences female teachers.

Ismai'l (2016) aimed at activating the international educational dimensions among the students who obtained a scholarship in King Saud University. Quantitative and qualitative approaches were adopted. A questionnaire was used for meeting the study's goals. The sample consists from experts who work at King Saud University and students enrolled at the latter university. It was found that providing international education shall enable students to address global challenges. It was found that there is much attention provided to the promotion of several international educational values in King Saud University. These values are ranked respectively based on the extent of promoting them as follows: compliance with human rights, interdependence, toleration, peace, and international understanding.

Abu E'laiwa (2017) aimed to shed a light on global citizenship. This issue has been receiving much attention globally. It is highly connected to globalism. The latter researcher aimed to shed much attention on an initiative that was launched by UNESCO. This initiative is called (the global citizenship education). The latter researcher aimed to shed a light on several issues related to global citizenship education, such as: multiculturalism, and accepting cultural diversity. The latter researcher aimed to distinguish between global and conventional citizenship. She suggests that global citizenship education shall participate in changing one's way of thinking, and ideology. She suggests that the latter education shall also participate in promoting international peace and equality. She suggests that the latter education shall also participate in achieving sustainable development.

Shijkazu et al. (2017) aimed at promoting knowledge about the International Association of Teaching and Curriculum which is headed by Shijkazu. It is a non-governmental association that is affiliated with UNESCO. The latter association perceives the world as a place that is full of conflicts and wars. It claims that wars and conflicts lead to a decline in society. The decline experienced by developing countries proves this point of view.

The latter association encourages its members to learn foreign languages in order to promote the international educational principles. That is done for preventing conflicts, and disputes and encouraging people to renounce all the forms of discrimination and violence. The latter association advocates for setting and promoting a common philosophy that involves peaceful coexistence and acceptance for the other. The latter philosophy involves peace, respecting humans, democracy, equality, and international cooperation and understanding. The latter association advocates for promoting this philosophy among people of all age categories.

El-Jezawi (2017) aimed to shed a light on the change that has occurred upon the conventional meaning of citizenship. The conventional meaning of citizenship is associated with granting several political and civil rights to a citizen. This change occurred due to several global changes. The latter researcher identified the meaning of several concepts related to global citizenship. She advocates for the acceptance of multiculturalism and addressing problems from a global perspective. She suggests that Arab institutions must participate in promoting international educational principles. For instance, they should seek promoting international peace, equality, toleration and respect for the culture of dialogue with the other.

\subsection{Foreign Studies}

Acosta (2011) aimed to explore the role of international education in the community colleges located in California from the perspective of executive managers. He also aimed to explore the reality of international education in these colleges and significance of providing it. In addition, he aimed to identify the impact of international education on the legislative policy in these colleges. Interviews were conducted to collect data. The sample consists from several executive managers who work at the community colleges located in California. It was found that international 
education is increasingly provided in these colleges. It was found that international education has a significant impact on the educational process. It was found that leadership plays a significant role in improving the quality of the provided international education. The latter researcher found that international education should be provided in the colleges of all states.

Jabbar (2012) aimed to shed a light on international education in the University of Jordan. A field survey was conducted. The latter researcher adopted qualitative and quantitative approaches. Interviews were conducted with students and a questionnaire was developed for collecting data. The sample consists from several Asian, American, and European students who are enrolled in the University of Jordan. The sample also consists from several faculty members who work at the University of Jordan. It was found that international education plays a significant role in promoting cultural awareness and knowledge about global affairs. It was found that international education plays a significant role in achieving personal growth, and career advancement.

Dwayne (2016) aimed at examining the way in which international education programs have been framed in British Columbia by media institutions and the government. The latter researcher used the content analysis method. For instance, he analyzed several governmental documents. These documents were obtained from local media sources. Thus, the sample consists from several governmental documents that were obtained from local media sources. These documents deal with international education. It was found that there isn't adequate cooperation between the government and media institutions in terms of international educational programs.

Weidman (2016) aimed to establish a series of frameworks that participate in enhancing international education and enabling people to understand educational and social changes. The sample consists from several scholars, and practitioners who are specialized in the field of international education. It also consists from finance agents and makers of educational policies.

The latter researcher provided a description for the main trends in international education. Then, he made a discussion for the post-2015 international education-related trends which were issued by the United Nations agencies. Then, he identified the conceptual foundations of international education. He also identified the relationship between these foundations and the historical background of comparative education and international education. It was found that providing international education shall positively affect the educational systems.

Yu- Chih (2017) aimed to conduct a comparison between comparative education and international education. He aimed to conduct this comparison in terms of theory, practices and methods. In order to conduct this comparison, the latter researcher reviewed the book written by Phillips and Schwe is furth (2014). According to the latter authors, comparative studies usually have an international nature. They also suggest that international studies are implicitly comparative. In addition, Yu- Chih (2017) discussed the similarities and differences between several cultures based on the views of a French philosopher

Chrystal (2017) aimed to examine international higher education partnerships through a mutuality lens. He conducted this examination based on management strategies and organizational theories. A qualitative inquiry method was used. The sample consists from the partnerships of a US university. It was found that that it is highly significant to establish such partnerships, and promote cultural exchange, and stakeholder engagement. It was found that that it is highly significant to choose the right partners.

\subsection{A Brief Summary for the Previous Studies and the Contribution of the Present Study}

The aforementioned studies vary in terms of goals, variables, and spatial dimensions. For instance, Ismai'l (2016) aimed to develop a proposed model for promoting international educational principles among the students enrolled in King Saud University. He also aimed to identify the significance of international education. As for Al-Kaltham (2016), he aimed to explore the extent of listing global educational concepts in the social and national sciences curricula of the intermediate stage in Saudi schools.

It should be noted that the aforementioned studies vary in terms of spatial dimensions. For instance, some studies were conducted in USA, whereas others were conducted in the United States of America (USA). Other studies were conducted in Britain. It should be noted that the aforementioned studies vary in terms of the adopted approach. For instance, some studies adopted quantitative approach, whereas other studies adopted a qualitative approach. As for the present study, it adopted a descriptive approach.

It should be noted that the aforementioned studies vary in terms of instrument. For instance, some studies used a questionnaire, whereas other studies used the interview method. Other studies used the observation method. Some previous studies used the content analysis method.

The aforementioned studies were reviewed in order to enrich the theoretical framework of the present study. The present study is one of the first few studies that shed a light on the role of Jordanian public universities in promoting 
international educational principles from the perspective of the faculty members.

\section{The Study's Methodology}

The present study adopted a descriptive approach.

\subsection{The Study's Population}

The population of the present study involves all the faculty members who work at three Jordanian public universities (i.e. the University of Jordan, Yarmouk University and Mu'tah University). These members were selected during the academic year of 2018 / 2019. According to the statistics issued by the Jordanian Ministry of Education for the latter academic year, the study's population consists from 10129 faculty members.

\subsection{The Study's Sample}

A sample was selected through using the random stratified method. It consists from 300 faculty members. Table 1 . presents information about the sample of the present study.

Table 1. Distribution of the sample in accordance with the type of faculty, academic rank and gender

\begin{tabular}{|c|c|c|c|c|c|c|c|c|c|c|}
\hline \multirow[t]{3}{*}{ Type of faculty } & \multirow[t]{3}{*}{ Academic rank } & \multirow[t]{2}{*}{ University } & \multirow{2}{*}{\multicolumn{2}{|c|}{$\begin{array}{l}\text { The University } \\
\text { of Jordan }\end{array}$}} & \multirow{2}{*}{\multicolumn{2}{|c|}{ Yarmouk University }} & \multirow{2}{*}{\multicolumn{2}{|c|}{$\begin{array}{l}\text { Mu'tah } \\
\text { University }\end{array}$}} & \multirow{2}{*}{\multicolumn{2}{|c|}{ Total }} \\
\hline & & & & & & & & & & \\
\hline & & Gender & Frequency & Percentage \% & Frequency & Percentage \% & Frequency & Percentage $\%$ & Frequency & Percentage \% \\
\hline Scientific & Professor & Male & 14 & 4.7 & 12 & 4.0 & 4 & 1.3 & 30 & 10.0 \\
\hline \multirow[t]{5}{*}{ faculties } & & Female & 7 & 2.3 & 5 & 1.7 & 7 & 2.3 & 19 & 6.3 \\
\hline & Associate & Male & 15 & 5.0 & 13 & 4.3 & 8 & 2.7 & 36 & 12.0 \\
\hline & professor & Female & 10 & 3.3 & 8 & 2.7 & 6 & 2.0 & 24 & 8.0 \\
\hline & Assistant & Male & 13 & 4.3 & 7 & 2.3 & 11 & 3.7 & 31 & 10.3 \\
\hline & professor & Female & 7 & 2.3 & 12 & 4.0 & 6 & 2.0 & 25 & 8.3 \\
\hline Humanitarian & Professor & Male & 14 & 4.7 & 8 & 2.7 & 6 & 2.0 & 28 & 9.3 \\
\hline \multirow[t]{5}{*}{ faculties } & & Female & 5 & 1.7 & 10 & 3.3 & 8 & 2.7 & 23 & 7.7 \\
\hline & Associate & Male & 10 & 3.3 & 13 & 4.3 & 8 & 2.7 & 31 & 10.3 \\
\hline & professor & Female & 5 & 1.7 & 6 & 2.0 & 8 & 2.7 & 19 & 6.3 \\
\hline & Assistant & Male & 4 & 1.3 & 6 & 2.0 & 7 & 2.3 & 17 & 5.7 \\
\hline & professor & Female & 6 & 2.0 & 5 & 1.7 & 6 & 2.0 & 17 & 5.7 \\
\hline Total & & & 110 & 36.7 & 105 & 35.0 & 85 & 28.3 & 300 & 100.0 \\
\hline
\end{tabular}

\subsection{The Study's Instrument}

The present study aimed to explore the role of Jordanian public universities in promoting international educational principles from the perspective of the faculty members. In order to achieve the study's goals, the researchers of the present study reviewed the relevant previous studies. Through reviewing the studies conducted by Jabbar (2012), and El-Jezawi (2017), the researchers developed a questionnaire that consists from thirty (30) statements. In addition, the three point Likert scale was adopted. This scale consists from three categories; high, moderate, and low.

\subsection{The Instrument's Validity}

In order to check the instrument's validity, the instrument was passed to ten (10) experts who are specialized in relevant fields. That was done to obtain those experts' opinions and comments about the instrument's structure, language, and clarity. All the experts' opinions and comments were taken into consideration and several modifications were made in the light of them.

\subsection{The Instrument's Reliability}

In order to measure the instrument's reliability, the overall value of Cronbach's Alpha coefficient was calculated. The latter value is 0.893

\subsection{The Study's Variables}

The variables of the present study are represented in the following:

1)- The independent variable: The role of Jordanian public universities in promoting international educational principles.

2)- The dependent variable: The attitude of the faculty members who work at three Jordanian public universities 
3)- Mediating variables:

Gender: Males and females.

Type of faculty: Humanitarian and Scientific faculties

Academic rank: Professor, associate professor, and assistant professor

\subsection{Statistical Analysis Methods}

In order to meet the study's goals, the SPSS program was used for analyzing the study's data. In addition, the relevant statistical methods were used. These methods include the following:

1)-Frequencies and percentages were calculated. They were calculated to describe the respondents' characteristics

2)-Arithmetic means and standard deviations were calculated. They were calculated to identify the respondents' attitudes towards each item of the questionnaire's items

3)-The overall value of Cronbach's Alpha coefficient was calculated. It was calculated to identify the instrument's reliability.

4)- The t-test for independent samples was conducted. It was conducted to identify the statistical significance of the differences between two independent groups.

5)- One-way ANOVA analysis was conducted. It is usually used for identifying the statistical significance of the differences between three independent groups or more.

6)-The least significant difference (LSD) test was conducted.

7)- The three point Likert scale was adopted to identify respondents' attitudes. Therefore, means were classified based on the following criteria:

High: 2.34 or more

Moderate:2.33 - 1.67

Low: 1.66 or less.

\section{The Study's Results}

Through this part, the researchers presented the results of the present study:

\subsection{Results Related to the Study's First Question}

The study's first question is listed below:

Q.1)- What is the role of Jordanian public universities in promoting international educational principles from the perspective of the faculty members?

In order to answer the study's first question questions, arithmetic means and standard deviations were calculated. In addition, ranks and levels were identified. These results are presented in table (2) below:

Table 2. Arithmetic means, standard deviations, ranks and levels that concern the first question

\begin{tabular}{|c|c|c|c|c|c|}
\hline No. & Statement & $\begin{array}{l}\text { Arithmetic } \\
\text { mean }\end{array}$ & $\begin{array}{l}\text { Standard } \\
\text { deviation }\end{array}$ & Level & Rank \\
\hline 6 & $\begin{array}{l}\text { The university exchanges faculty members with universities located in } \\
\text { multicultural countries }\end{array}$ & 2.44 & 0.699 & High & 1 \\
\hline 23 & $\begin{array}{l}\text { The university provides knowledge based on the international } \\
\text { educational principles }\end{array}$ & 2.32 & 0.673 & Moderate & 2 \\
\hline 14 & $\begin{array}{l}\text { The university obliges its faculty members in each department to take } \\
\text { English language courses }\end{array}$ & 2.31 & 0.696 & Moderate & 3 \\
\hline 17 & $\begin{array}{l}\text { The university promotes acceptance for the other among the faculty } \\
\text { members }\end{array}$ & 2.29 & 0.770 & Moderate & 4 \\
\hline 24 & $\begin{array}{l}\text { The university seeks promoting international educational principles } \\
\text { through its activities. }\end{array}$ & 2.27 & 0.680 & Moderate & 5 \\
\hline 7 & $\begin{array}{l}\text { The university provides lectures that address international education- } \\
\text { related issues }\end{array}$ & 2.26 & 0.695 & Moderate & 6 \\
\hline 21 & $\begin{array}{l}\text { The university provides support for the promotion of international } \\
\text { educational principles }\end{array}$ & 2.24 & 0.712 & Moderate & 7 \\
\hline
\end{tabular}


The university engages its faculty members in international conferences related to human rights

The university provides courses that shed a light on other cultures and races

The university promotes knowledge about other cultures among its faculty members

The university seeks promoting the culture of peaceful dialogue and coexistence

The university provides research scholarships for conducting human right-related research

The university seeks providing a mandatory course that promote international educational principles

The university obliges its faculty members to address international peacerelated issues

The university provides courses that promote knowledge about international education-related documents

The university seeks making plans that promote international cooperation and understanding

The university enlightens its faculty members about the significance of promoting knowledge among students about human rights

The university provides its faculty members with training about international education principles

The university seeks identifying students' attitudes towards international education principles

The university's curricula include information about contemporary issues

The university seeks promoting acceptance for multiculturalism

Each semester, the university provides its faculty members with plans

that include international education-related references

The university propose international education-related ideas and uploads

them on its official website

The university provides its faculty members with financial resources for

9 exchanging expertise with the faculty members working in universities

located in multicultural countries

The university allocates money for the research conducted by its faculty members about international education

Total
2.23

2.21

2.20

2.19

2.17

2.16

2.15

2.14

2.12

2.10

2.09

2.07

2.06

2.04

2.01

1.98

1.95

2.17

$\begin{array}{lll}0.721 & \text { Moderate } & 8 \\ 0.741 & \text { Moderate } & 9 \\ 0.721 & \text { Moderate } & 10 \\ 0.714 & \text { Moderate } & 11 \\ & & \\ 0.706 & \text { High } & 12 \\ 0.685 & \text { Moderate } & 13 \\ & & \\ 0.740 & \text { High } & 14\end{array}$

$0.737 \quad$ Moderate 15

$0.723 \quad$ Moderate $\quad 16$

$0.725 \quad$ Moderate $\quad 17$

$0.742 \quad$ High $\quad 18$

$0.770 \quad$ Moderate $\quad 19$

$0.735 \quad$ Moderate 20

$0.742 \quad$ Moderate 21

$0.710 \quad$ Moderate 22

$0.740 \quad$ Moderate 23

$0.667 \quad$ Moderate 24

$0.724 \quad$ Moderate 25

$0.449 \quad$ Moderate

Based on table (2), the means that are within the range of $(2.40$ - 1.95). Statement 6 shows the highest mean, which is 2.40. It is considered a high mean. The latter statement states the following: (The university exchanges faculty members with universities located in multicultural countries). As for the other means, they are moderate. Statement 12 shows the least mean, which is 1.95 . The latter statement states the following: (The university allocates money for the research conducted by its faculty members about international education). As for the overall mean, it is 2.17 which is considered moderate. That indicates that Jordanian public universities play a moderate role in promoting international educational principles from the perspective of the faculty members.

This result can be attributed to the fact that these universities exchange faculty members with universities located in multicultural countries. Such exchange is carried out in order to exchange educational expertise with the faculty members working in universities located in developed countries. It is also carried out for establishing good relationships with universities and cooperating with them. It is carried out for gaining knowledge about the modern educational means which can effectively promote international educational principles. These principles include acceptance for the other.

As for the result of statement 12, this result is attributed to the fact that Jordanian public universities suffer from budget deficiency. Such a deficiency is attributed to the rise in the operating expenses. It is also attributed to the poor attention provided to international education and the decrease of the governmental financial support for university education. The result of the study's first question is consistent with the results concluded by Acosta (2011), Ismai'l (2016), and Al-Kaltham (2016). 


\subsection{Results related to the study's second question:}

The study's second question is listed below:

Q.2)- Is there any statistically significant difference between respondents' attitudes which can be attributed to their gender, type of faculty, or academic rank?

\section{Statistically significant difference which can be attributed to gender}

In order to answer the study's second question questions, arithmetic means and standard deviations were calculate in accordance with the respondents' gender. In addition, the t-test was conducted to identify the statistical significance of the differences between these means. These results are presented in table (3) below:

Table 3. Results of the t-test for identifying the statistical significance of the differences between means in accordance with the respondents' gender

\begin{tabular}{lllllll}
\hline Gender & Frequency & $\begin{array}{l}\text { Arithmetic } \\
\text { mean }\end{array}$ & $\begin{array}{l}\text { Standard } \\
\text { deviation }\end{array}$ & T-value & $\begin{array}{l}\text { Degree of } \\
\text { Freedom }(\mathrm{df})\end{array}$ & Sig. \\
\hline Male & $\mathbf{1 7 3}$ & $\mathbf{2 . 1 8}$ & $\mathbf{0 . 4 4 2}$ & $\mathbf{0 . 0 3 5}$ & $\mathbf{2 9 8}$ & $\mathbf{0 . 9 7 2}$ \\
Female & $\mathbf{1 2 7}$ & $\mathbf{2 . 1 7}$ & $\mathbf{0 . 4 6 0}$ & & & \\
\hline
\end{tabular}

Based on table (3), the statistical significance is $\mathbf{0 . 9 7 2}$ which is greater than 0.05 . That means that there isn't any statistically significant difference between the respondents' attitudes which can be attributed to gender. That means that male and female faculty members have similar views about the role of Jordanian public universities in promoting international educational principles.

That indicates that male and female faculty members seek finding methods that can enhance the international education being provided. They are also keen to develop traits of professional scientists within students regardless of their origins. They are also keen to improve the quality of university education in Jordan. They are keen to provide an education that keeps up with the contemporary developments. They are keen to promote international educational principles. The latter result is inconsistent with the result concluded by Jaydoory (2012).

\section{Statistically significant difference which can be attributed to the type of faculty}

In order to answer the study's second question questions, arithmetic means and standard deviations were calculate in accordance with the respondents' type of faculty. In addition, the t-test was conducted to identify the statistical significance of the differences between these means. These results are presented in table (4) below:

Table 4. Results of the t-test for identifying the statistical significance of the differences between means in accordance with the respondents' type of faculty

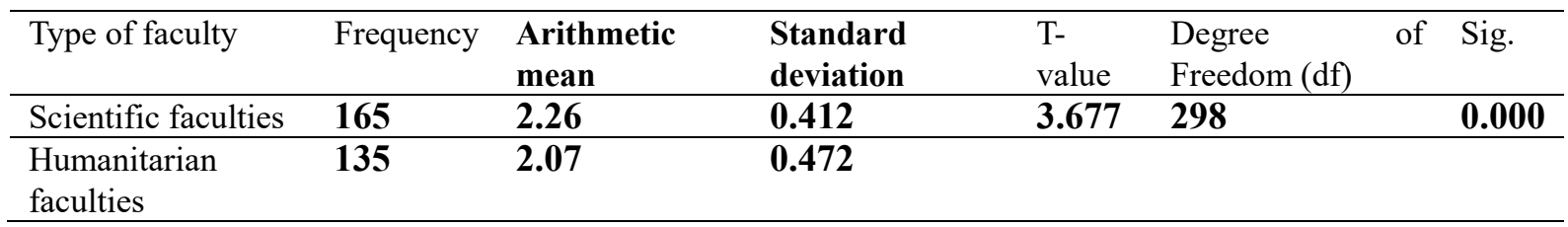

Based on table (4), the statistical significance value is $\mathbf{. 0 0 0 0}$ which is less than 0.05 . That means that there is a statistically significant difference between the respondents' attitudes towards the role of Jordanian public universities in promoting international educational principles which can be attributed to the type of faculty. The latter differences are for the favor of the ones who work in scientific faculties.

That indicates that respondents have work in scientific faculties have more positive attitudes than the ones working in humanitarian faculties. That may be attributed to the fact that the faculty members working in scientific faculties seek adopting modern methods in teaching. They also seek providing education that keeps up with contemporary developments. They also seek providing education that develops students' personality and promotes international educational principles. In addition, they seek promoting acceptance for multiculturalism and respect for the other.

\section{Statistically significant difference which can be attributed to the academic rank}

In order to answer the study's second question questions, arithmetic means and standard deviations were calculate in accordance with the respondents' academic rank. In addition, the t-test was conducted to identify the statistical 
significance of the differences between these means. These results are presented in table (5) below:

Table 5. Results of the t-test for identifying the statistical significance of the differences between means in accordance with the respondents' academic rank

\begin{tabular}{llll}
\hline Type of faculty & Frequency & Arithmetic mean & Standard deviation \\
\hline Professor & $\mathbf{1 0 0}$ & $\mathbf{2 . 1 0}$ & $\mathbf{0 . 4 6 5}$ \\
Associate professor & $\mathbf{1 1 0}$ & $\mathbf{2 . 3 3}$ & $\mathbf{0 . 4 1 4}$ \\
Assistant professor & $\mathbf{9 0}$ & $\mathbf{2 . 1 2}$ & $\mathbf{0 . 4 2 7}$ \\
\hline
\end{tabular}

Based on table (5), it can be noticed that there appear to be differences between the respondents' attitudes towards the role of Jordanian public universities in promoting international educational principles which can be attributed to their academic rank. In order to explore the statistical significance of these differences, one-way ANOVA analysis was conducted. The results of the latter analysis are presented in table (6) below:

Table 6. The results of one-way ANOVA analysis for identifying the statistical significance of these differences between respondents' attitudes which can be attributed to their academic rank

\begin{tabular}{llllll}
\hline Source of variance & Sum of squares & Degree of freedom $(\mathrm{df})$ & Mean square & F value & Sig. \\
\hline Between groups & $\mathbf{3 . 9 3 4}$ & $\mathbf{2}$ & $\mathbf{1 . 9 6 7}$ & $\mathbf{1 0 . 3 7 4}$ & $\mathbf{0 . 0 0 0}$ \\
Within groups & $\mathbf{5 6 . 3 1 9}$ & $\mathbf{2 9 7}$ & $\mathbf{0 . 1 9 0}$ & & \\
Total & $\mathbf{6 0 . 2 5 3}$ & $\mathbf{2 9 9}$ & & & \\
\hline
\end{tabular}

Based on table (6), it can be noticed that the statistical significance value is 0.000 which is less than the statistical significance level of $(a=0.05)$. That means that there is a statistically significant difference - at the statistical significance level of $(a=0.05)$ - between the respondents' attitudes towards the role of Jordanian public universities in promoting international educational principles which can be attributed to academic rank. In order to identify the rank that the difference is in favor for, the least significant difference (LSD) test was conducted. The results of the latter test are presented in table (7) below:

Table 7. The results of the least significant difference (LSD) test

\begin{tabular}{llll}
\hline Academic rank & Arithmetic mean & Associate professor & Assistant professor \\
\hline Professor & $\mathbf{2 . 1 0}$ & $*$ & $*$ \\
Associate professor & $\mathbf{2 . 3 3}$ & & $*$ \\
Assistant professor & $\mathbf{2 . 1 2}$ & $*$ & \\
\hline
\end{tabular}

(*) This sign means that the difference is statistically significant

Based on table (7), there is a statistically significant difference - at the statistical significance level of $(a=0.05)$ between the respondents' attitudes towards the role of Jordanian public universities in promoting international educational principles which can be attributed to academic rank. The latter difference is for the favor of the associate professors. That indicates that associate professors have more positive attitudes than professors and assistant professors. That indicates that associate professors aims to promote the culture of dialogue, positive community values, and international educational principles and deliver global citizenship education. The latter result is in agreement with the result concluded by Jaydoory (2012).

\section{Recommendations}

In the light of the aforementioned results, the researchers of the present study recommend the following:

1)- Exerting more efforts by the administrations of Jordanian public universities to promote international educational principles.

2)- Providing more attention for international education in Jordanian universities. That should be done through holding seminars in order for faculty member to attend and hold discussions about international educational principles and concepts. Such seminars shall enrich the knowledge that faculty members have in this regard.

3)- Promoting awareness among faculty members about the significance of addressing international education- 
related issues in their lectures.

\section{References}

Abed Al-Hay, R. (2013). Global education as one of the third millennium requirements. Amman. Al-Waraq publishing and distribution house.

Abu E'laiwa, N. (2017). Ideas about global citizenship. Development and Childhood Journal, 8(29), 107-121. Egypt.

Acosta, M. (2011). The Role of International Education in California Community Colleges: Perspectives of College Leaders. Doctor of Education, Pepperdine university.

Al Eid, L., \& AlZboon, M. (2018). Role of Jordanian Universities in Facing Cultural Globalization. Modern Applied Science, 12(7), 165-195.

Al- Hazaymeh, F. (2017). The role of Jordanian universities' administrations inactivating scientific research and proposals for development. The Federation of Arab Universities Journal for psychology and education - Syria, 15(2), 168-198.

Al- Tarawneh, E. (2010). Visions and ideas related to university education. Amman. Amjad publishing and distribution house.

Al-Buhy, F. (2014). International education. Alexandria. Al-Ma'refah publishing and distribution house.

Al-Kaltham, M. (2016). Global educational concepts in the social and national sciences curricula of the intermediate stage in the schools located in the Kingdom of Saudi Arabia. The Journal of the Psychology and Education Mission. Saudi Arabia, 131, 54-150.

Al-Milad, Z. (2013). Cross cultural knowledge: Idea, experience and foundation. The cultural dialogue Journal, 6-20

Al-Shal, M. (2012). Methods for activating the efforts and programs of the international educational organizations in the higher education field in Egypt in the light of global experiences. The Educational Faculty Journal, (46), 1-27. Tanta University.

Azab, M (2011). University education and development-related issues. Egypt. Anglo Library

Dwayne, C. (2016). The Discursive Fraiming of International Education Programs in British Columbia. Canadian Journal of Educational Administration and Policy, 1(180), 169-201.

El-Jezawi, D. (2017). Global citizenship, and its future prospects in the Arab World. Development and Childhood Journal - Egypt, 8(29), 157-165.

Isma'il, M. (2016). Activating the international educational dimensions among the students who obtained a scholarship: King Saud University as a model. The Journal of the Arab Education Future, 23(105), 219-308. Egypt.

Jabbar, S. (2012). International Education: A Case Study from The University of Jordan. Education, 1(33), 202220.

Jaydoory, S. (2012). Promotion of global citizenship values among university students. The Social Affairs Journal, 29(116), 77-111.

Lasheen, M., \& Abed Al-Jawad, M. (2012). The mechanisms used for promoting a culture of peace education through university education in the light of international education requirements: A field study. The faculty of education Journal, 73(42), 27-97. Banha University.

Mwangi, G., \& Chrystal, A. (2017). Partner Positioning: Examining International Higher Education Partnership Through A Mutuality Lens. Review of Higher Education, 1(41), 33-60.

Nasr, A. (2013). Research issues in the international education field from a contemporary perspective. The Journal of Education, 16(46). 191-240. Egypt.

Shijkazu, T., Abed Al-Kafi, A., \& Fathi, Y. (2017). Education in the 21 stcentury in the international community. Reading and Knowledge Journal, 1(188), 22-38. Egypt.

Weidman, J. (2016). Framing International Development Education in the Post- 2015 Era: Suggestion for Scholars and Policymakers. Asia Pacific Review, 3(17), 403-412.

Yas, A. (2002). Dialogue among civilizations in the age of globalization. Cairo. Nahdet Maser publishing and distribution house. 
Yu, Chih, L. (2017). International Education Comparison: An Intellectuall Tradition and its Contemporary Consideration. Discourse: Studies in the Cultural Politics of Education, 6(38), 955-963.

\section{Copyrights}

Copyright for this article is retained by the author(s), with first publication rights granted to the journal.

This is an open-access article distributed under the terms and conditions of the Creative Commons Attribution license (http://creativecommons.org/licenses/by/4.0/). 